Çocuklarda beslenme ve ağız bakım alışkanlıkları ile etkileyen faktörlerin değerlendirilmesi

\section{Evaluation of children dietary and oral hygiene habits with affecting factors}

\section{Dt. Aydın Akçakoca}

Marmara Üniversitesi, Diş Hekimliği Fakültesi, Periodontoloji Ana Bilim Dalı, İstanbul Orcid ID: 0000-0002-5296-5651 Dr. Öğr. Üyesi Süleyman Emre Meşeli İstanbul Aydın Üniversitesi, Diş Hekimliği Fakültesi, Periodontoloji Ana Bilim Dalı, İstanbul

Orcid ID: 0000-0002-8922-155X

\section{Dr. Öğr. Üyesi Hatice Selin Yıldırım}

Marmara Üniversitesi, Diş Hekimliği Fakültesi, Periodontoloji Ana Bilim Dalı, İstanbul

Orcid ID: 0000-0001-5650-3107

\section{Dt. Nil Ceren Mungan}

Marmara Üniversitesi, Diş Hekimliği Fakültesi, Pedodonti Ana Bilim Dalı, İstanbul

Orcid ID: 0000-0002-1035-4174

\section{Prof. Dr. Serap Akyüz}

Marmara Üniversitesi, Diş Hekimliği Fakültesi,

Pedodonti Ana Bilim Dalı, İstanbul

Orcid ID: 0000-0002-1358-0150

\section{Prof. Dr. Leyla Kuru}

Marmara Üniversitesi, Diş Hekimliği Fakültesi, Periodontoloji Ana Bilim Dalı, İstanbul

Orcid ID: 0000-0002-7599-2409

Geliş tarihi: 02 Haziran 2020

Kabul tarihi: 09 Eylül 2020

doi: 10.5505/yeditepe.2021.48403

\section{Yazışma adresi:}

Dr. Öğr. Üyesi Hatice Selin Yıldırım

Marmara Üniversitesi, Diş Hekimliği Fakültesi,

Periodontoloji Ana Bilim Dalı, İstanbul

Başıbüyük Mahallesi, Başıbüyük Yolu 34854

İstanbul - Türkiye

Tel: 05335426812

E-posta: selin.yildirim@marmara.edu.tr

\section{ÖZET}

Amaç: Bu çalışmada, çocuk hastaların dental ve periodontal durumları ile ağız bakım alışkanlıklarını saptamak, bunları etkileyebilecek çocuğa ve ebeveynlerine ait faktörleri değerlendirerek aralarındaki olası ilişkiyi araştırmak amaçlandı.

Gereç ve Yöntem: Çalışma popülasyonunu dahil edilme kriterlerine uygun 150 çocuk oluşturdu. Periodontal durumlarına göre sağlıkı( $n=70)$ ve gingivitisli $(n=80)$ olacak şekilde gruplara ayrıldı. Demografik veriler, beslenme ve ağız bakım alışkanlıkları, ebeveynlerin eğitim seviyeleri anket formuna kayıt edildi. Dental durumun değerlendirilmesi için daimi dişlerde DMF-T/DMF-S, süt dişlerinde df-t/df-s indeksleri, periodontal durumun değerlendirilmesi için plak indeks (Pi), gingival indeks (Gi) ve community periodontal indeks (CPI) ölçüldü.

Bulgular: Çalışmaya 8-14 yaş aralığındaki 150 çocuk (kız/ erkek=83/67) dahil edildi. Cinsiyetlerine göre, beslenme ve fırçalama alışkanlıkları karşılaştıııldığında günlük ara öğün sayısı erkeklerde kızlara göre yüksek bulunurken $(p<0,05)$, klinik parametreler açısından bu 2 grup arasında fark bulunmadığı görüldü $(p>0,05)$. Periodontal durumlarına göre incelendiğinde, kızların \%56,3'ü erkeklerin \%43,8'i gingivitisli olarak teşhis edildi. Beslenme alışkanlıklarının gingivitisli ve sağlıklı gruplarda benzer olduğu $(p>0,05)$, gingivitislilerin fırçalama süresinin düşük olduğu( $p<0,05)$, Pi, Gi ve $C P I$ değerlerinin sağlıklılara göre yüksek olduğu $(p<0,01)$, dental parametreler açısından fark olmadığı saptandı $(p>0,05)$. Çocukların beslenme ve fırçalama alışkanlıklarına göre periodontal ve dental parametrelerde fark bulunmadı $(p>0,05)$. Fırçalama sıklığına göre periodontal parametrelerde fark saptanırken $(p<0,01)$, dental parametrelerde fark saptanmadı $(p>0,05)$.

Sonuç: Araştırmanın yürütüldüğü çocuklarda, beslenme alışkanlıklarının karbonhidrattan zengin, ara öğün sayısının yüksek olduğu ve ağız hijyeni gerekliliklerini yerine getirmede yetersiz kaldıkları görüldü. Çalışmanın sınırları dahilinde bulgularımız, bu beslenme alışkanlığının çürük oluşumunda tek başına yeterli olmadığı, periodontal hastalığın önlenmesinde ağız bakım alışkanlığının önemini vurgulamaktadır.

Anahtar kelimeler: Çocuk, beslenme alışkanlığı, ağız bakımı SUMMARY

Aim: The aim of this study was to evaluate dietary and oral hygiene habits of children and to investigate possible relationship between the children's habits and affected factors associated with their parents

Methods: The study population consisted of 150 children, who met the inclusion criteria and were divided into health$y(n=70)$ and gingivitis $(n=80)$ groups. Demographic data, dietary and oral hygiene habits, parents' education levels were collected by questionnaire. DMF-T/DMF-S, df-t/df-s, plaque, gingival and community periodontal indices were recorded. Results: 150 children (girl/boy=83/67) between the ages of 8-14 years were included in the study. According to gender, the number of daily snacks was higher in boys $(p<0.05)$, but there was no difference in clinical parameters between boys 
and girls ( $p>0,05)$. According to periodontal status, $56 \cdot 3 \%$ of girls and $43,8 \%$ of boys were diagnosed with gingivitis. Dietary habits were similar between gingivitis and healthy groups ( $p>0.05$ ). Gingivitis patients had low brushing-time $(p<0.05)$ and also periodontal parameters were higher $(p<0,01)$. There was no difference in dental parameters ( $p>0.05$ ). When children were grouped by the dietary and brushing habits, no difference were observed in both periodontal and dental parameters $(p>0.05)$. According to the frequency of tooth-brushing, significant difference was present in periodontal parameters $(p<0.01)$ but absent in dental parameters $(p>0,05)$.

Conclusion: It was concluded that dietary habits of study population were rich in carbohydrates, the number of snacks was high and oral-hygiene practices were inadequate. Our findings revealed the importance of oral hygiene habits in preventing periodontal disease in children.

Keywords: Child, dietary habits, oral hygiene

\section{Giriş}

Ağız ve diş sağlığl; diş ve dişeti, sert ve yumuşak damak, ağız mukozası, dil, dudaklar, tükürük bezleri, çiğneme kasları ve nörovasküler ağ sisteminin sağlığını içeren geniş kapsamlı bir kavramdır.' Geçmişte ağız ve diş sağlığı bireyin genel sağlığından ayrı görülmüş² olsa da günümüzde genel sağlığın ayrılmaz bir parçası olduğu ve bireyin çocukluk çağındaki ağız sağlığının ergenlik ve yetişkinlik dönemindeki ağız sağlığı durumunun güçlü bir belirleyicisi olduğu kabul edilmiş bir gerçektir. ${ }^{3}$

Dünya genelinde en sık görülen ağız hastalıkları olan diş çürükleri ve periodontal hastalıklar multifaktöriyel karaktere sahiptir. Çocuklarda da görülen bu hastalıklar, tedavi edilmediklerinde çocuğun beslenme ve gelişimini olumsuz etkileyerek yaşam kalitesini düşürebilmektedir. ${ }^{4,5}$

Çocuklarda beslenme alışkanlıklarının ağız sağlığının yanı sıra diyabet, obezite, kalp hastalıkları gibi beslenmeyle ilişkili kronik hastalıklar açısından da önemli olduğu global bir gerçek olarak karşımıza çıkmaktadır. ${ }^{6}$ Çocuklarda ağız bakım alışkanlıkları, çocuğun yaşı, cinsiyeti, ebeveynlerin eğitim seviyesi ve hem çocuğun hem de ebeveynlerin beslenme alışkanlıkları gibi pek çok faktörden etkilenebilen ve çocuğun gelecekteki ağız sağlığı durumunun belirleyicisi olan kapsamlı bir kavramdır., 2,7

Hem diş çürükleri hem de periodontal hastalıklar için birincil etiyolojik faktör mikrobiyal dental plak olsa da, bu hastalıkların oluşmasında bireye ait genetik, davranışsal, psikososyal ve sosyoekonomik faktörlerin de etkili olduğu gösterilmiştir. ${ }^{8-10}$ Mikrobiyal dental plağın diş fırçalama, ara yüz temizliği gibi ağız bakım alışkanlıklarıyla mekanik olarak uzaklaştırıması, bu hastalıklardan korunmada birincil öneme sahiptir. Ebeveynlerin eğitim seviyesinin ve beslenme alışkanlıklarının çocuğun beslenme alışkanlığı ile ilişkisi farklı araştırmalarda gösterilmiştir.11-14 Annenin ağız bakımı, beslenme alışkanlığı ve eğitim seviyesi ile çocuğun ağız sağlığı ve beslenme alışkanlığı arasında doğrudan pozitif yönlü bir ilişkinin varlığı ortaya konmuştur. ${ }^{11-14}$ Marshall ve ark..$^{14}$ tarafından yapılan çalışmada, çürük görülen çocuklarda ailenin eğitim ve gelir seviyesinin daha düşük; annenin beden ağırlığının ve çocuğun gazlı içecek tüketim miktarının ise yüksek olduğu gözlenmiştir. Aynı çalışmanın bulguları çocukluk dönemi obezitesi ile çürük arasında da pozitif yönlü ilişkinin varlığını göstermektedir. ${ }^{14} \mathrm{Bu}$ bilgiler ışığında çalışmamızda çocuk hastaların dental ve periodontal durumları ile ağız bakım alışkanlıklarını saptamak ve bunları etkileyebilecek çocuğa ve ebeveynlerine ait faktörleri değerlendirerek aralarındaki olası ilişkiyi araştırmak amaçlandı.

\section{GEREÇ VE YÖNTEM}

Bu kesitsel çalışmanın protokolü Marmara Üniversitesi Diş Hekimliği Fakültesi Etik Kurulu tarafından onaylandı (27.03.2017/2017-83). Çalışma planı, Helsinki Bildirgesi'nde insan denekleriyle ilgili belirtilen ilkeler doğrultusunda tamamlandı.

\section{Hasta Seçimi ve Çalışma Grupları}

Çalışma popülasyonunu Marmara Üniversitesi Diş Hekimliği Fakültesi Pedodonti Anabilim Dalı Kliniği'ne Haziran 2017-Haziran 2018 arasında başvuran puberte dönemindeki çocuk hastalar ve ebeveynleri oluşturdu.

Çalışmaya dahil edilen çocuklarda:

- Çocukların ve velilerin çalışmaya gönüllü olarak katııım onayı vermeleri,

-Çocukların sistemik olarak sağlıklı olmaları,

-8-14 yaş aralığında olmaları,

-Periodontal olarak sağlıklı (panoramik radyografide kemik kaybı yok, gingival indeks $(\mathrm{Gi})^{15}$ ve community periodontal indeks (CPI) değerleri 0) veya gingivitisli olmaları (panoramik radyografide kemik kaybı yok, Gi değeri 1-3 arasında ve CPI değeri 1-2 arasında),

-Ortodonti tedavisi görmüyor olmaları,

-Son 6 ay içinde periodontal doku cevabını değiştirecek antibiyotik, antimikrobiyal veya antienflamatuvar ilaç kullanmamış olmaları,

-Son 6 ay içinde herhangi bir periodontal tedavi görmemiş olmaları,

-Kendi ağız bakımını yerine getirmeyi sınırlayan herhangi bir fiziksel veya mental engelin bulunmaması şartları arandı. Çalışma kriterlerine uygun olan ve çalışmaya dahil edilen çocuklarda herhangi bir işlem yapılmadan önce hem kendilerine hem de ebeveynlerine çalışma hakkında ayrıntıı sözlü ve yazılı bilgi verilerek, ebeveynlerden aydınlatılmış onam formu imzaları alındı.

Çalışma popülasyonunu Pedodonti Kliniği'ne başvuran 1253 çocuktan dahil edilme kriterlerini karşılayan 150 çocuk oluşturdu ve bu çocuklar periodontal durumlarına göre sağlıklı $(n=70)$ ve gingivitisli $(n=80)$ olacak şekilde 
gruplandırıldı.

\section{Çalışma Planı}

Araştırmaya dahil edilen çocukların demografik verileri, günlük ara öğün sayısı, günlük karbonhidrat içeren gıda ve şekerli içecek tüketim sıklığı, diş fırçalama sıklığı ve süresi, ebeveynlerin eğitim seviyesi ve ağız bakım alışkanlıklarını kayıt altına almak için 16 sorudan oluşan bir anket formu hazırlandı. Anketlerin doldurulmasını takiben ağız aynası, sond ve 0,5 mm çapında periodontal sonda (University of North Carolina PCPUNC15, Hu-Friedy Ins. Co., ABD) ile ağız içi muayeneleri yapıldı. Dental durumun değerlendirilmesi için Dünya Sağlık Örgütü (DSÖ) kriterlerine göre daimi dişlerde DMF-T/DMF-S, ${ }^{16}$ süt dişlerinde df-t/df-s ${ }^{17}$ indeksleri kayıt altına alındı. Diş yüzeylerinde biriken plak miktarının değerlendirilmesi için plak indeks (PI), ${ }^{18}$ periodontal durumun değerlendirilmesi için Gi ve CPI ölçüldü.

\section{İstatistiksel Analiz}

Bu çalışmada elde edilen bulguların istatistiksel analizinde SPSS 25 (IBM SPSS Statistics, IBM Corp., ABD) paket programı kullanıldı. Verilerin değerlendirilmesinde tanımlayıcı istatistikler; niteliksel değişkenler için sayı ve yüzde, niceliksel değişkenler için aritmetik ortalama, ortanca, standart sapma, minimum ve maksimum olarak verildi. Sayısal verilerin normal dağılım koşulunu sağlayıp sağlamadığı Kolmogorov Smirnov testiyle saptandı.

Gruplar arası niteliksel verilerin karşılaştırılması Ki-Kare ve Fisher's Exact Ki-Kare testi ile yapıldı. Normal dağılım göstermeyen niceliksel verilerin gruplar arası karşılaştırılmasında Mann-Whitney U testi kullanıldı. Normal dağıım sağlamayan niceliksel verilerin gruplar arası çoklu karşılaştırılmasında ise Kruskal-Wallis testi uygulandı. Sonuçlar \%95 güven aralığında ve istatistiksel anlamlılık $p<0,05$ düzeyinde değerlendirildi.

\section{BULGULAR}

Çalışmaya dahil edilen, 8-14 yaş aralığındaki (ortalama yaş $10,45 \pm 1,74) 150$ çocuktan 83'ü kız ve 67'si erkekti. Tablo 1'de tüm çocukların beslenme ve diş fırçalama alışkanlıkları ile ilgili veriler gösterilmektedir.

Çocukların \%88,7'sinde günlük ara öğün sayısının en az 1 olduğu, günde en az 1 kez karbonhidrat tükettiği ve $\% 70,6$ 'sının karbonhidrattan orta derecede zengin ve çok zengin ara öğün tükettiği gözlendi. Günlük şekerli içecek tüketmeyen çocukların oranı ise sadece $\% 22$ olarak bulundu. Fırçalama alışkanlığına bakıldığında, çocukların \%20,7 günde 2 kez diş fırçaladığı saptandı. Çocukların cinsiyetine göre beslenme ve fırçalama alışkanlıkları karşılaştırıldığında (Tablo 2) günlük ara öğün sayısı erkeklerde kızlara göre istatistiksel olarak anlamlı derecede yüksek bulunurken $(p<0,05)$, diğer beslenme ve fırçalama alışkanlıkları cinsiyetler arasında fark göstermedi $(p>0,05)$. Çocuklar periodontal durumlarına göre incelendiğinde, kızların \%56,3'ü erkeklerin \%43,8'i gingivitisli olarak teşhis edildi. Sağlıklı ve gingivitisli çocukların beslenme alışkanlıklarının benzer olduğu görülürken $(p>0,05)$, gingivitisli çocuklarda ortalama $1,52 \pm 1,05$ dakika olan fırçalama süresinin sağlıklı çocuklardan $(1,86 \pm 0,86$ dakika) istatistiksel olarak anlamlı düşük olduğu saptandı $(p<0,05)$ (Tablo 2$)$.

Tablo 1. Çocukların beslenme ve diş fırçalama alışkanlıkları

\begin{tabular}{|c|c|c|c|}
\hline & & $\mathbf{n}$ & $\%$ \\
\hline \multirow{5}{*}{$\begin{array}{l}\text { Günlük ara ög̈ün } \\
\text { Sayısı }\end{array}$} & Tüketmiyor & 17 & 11,3 \\
\hline & $1 \mathrm{kez}$ & 60 & 40,0 \\
\hline & 2 kez & 46 & 30,7 \\
\hline & $3 \mathrm{kez}$ & 24 & 16,0 \\
\hline & $4 \mathrm{kez}$ & 3 & 2,0 \\
\hline \multirow{7}{*}{$\begin{array}{l}\text { Günlük KH } \\
\text { tïketim sayısı }\end{array}$} & Tüketmiyor & 0 & 0,0 \\
\hline & $1 \mathrm{kez}$ & 10 & 6,7 \\
\hline & 2 kez & 36 & 24,0 \\
\hline & $3 \mathrm{kez}$ & 63 & 42,0 \\
\hline & $4 \mathrm{kez}$ & 27 & 18,0 \\
\hline & $5 \mathrm{kez}$ & 13 & 8,7 \\
\hline & $6 \mathrm{kez}$ & 1 & 0,7 \\
\hline \multirow{6}{*}{$\begin{array}{l}\text { Günlük ş̧ekerli } \\
\text { içecek } \\
\text { tülketim sayısı }\end{array}$} & Tüketmiyor & 33 & 22,0 \\
\hline & $1 \mathrm{kez}$ & 72 & 48,0 \\
\hline & 2 kez & 40 & 26,7 \\
\hline & 3 kez & 3 & 2,0 \\
\hline & 4 kez & 1 & 0,7 \\
\hline & $5 \mathrm{kez}$ & 1 & 0,7 \\
\hline \multirow{4}{*}{$\begin{array}{l}\text { Ara öğüindeki } \\
\text { KH çeşidi }\end{array}$} & KH tüketmiyor & 17 & 11,3 \\
\hline & KH fakir & 27 & 18,0 \\
\hline & KH orta & 47 & 31,3 \\
\hline & KH zengin & 59 & 39,3 \\
\hline \multirow{5}{*}{ Firçalama sıkhı̆ı } & Firçalamıyor & 15 & 10,0 \\
\hline & Haftada 2-3 & 31 & 20,7 \\
\hline & kez & & \\
\hline & Günde 1 kez & 73 & 48,7 \\
\hline & Günde 2 kez & 31 & 20,7 \\
\hline
\end{tabular}

KH: Karbonhidrat.

Çocukların ebeveynlerinin eğitim seviyesi incelendiğinde, anne ve babaların \%84'ünün lise ve üzeri eğitim aldığı, okuma-yazma bilmeme oranının annelerde \%4 babalarda \%1 olduğu saptandı. Ebeveynlerin eğitim seviyesine göre çocukların beslenme ve fırçalama alışkanlıkları incelendiğinde, ilköğretim ve altı eğitim seviyesine sahip anneler ile lise ve üzeri eğitim seviyesine sahip annelerin çocuklarında beslenme ve fırçalama alışkanlığı açısından istatistiksel olarak anlamlı fark bulunmadı $(p>0,05)$. Ilköğretim ve altı ile lise ve üzeri eğitim seviyesine sahip babaların çocuklarında beslenme alışkanlıkları açısından istatistiksel olarak anlamlı fark yoktu ( $p>0,05)$; ancak lise ve üzeri eğitim seviyesine sahip babaların çocuklarının ilköğretim ve altı eğitim seviyesine sahip babaların çocuklarına göre istatistiksel anlamlı olarak dişlerini daha düzenli fırçaladığı tespit edildi $(p<0,05)$.

Çocukların klinik periodontal ve dental parametrelerinin sunulduğu Tablo 3 'te, 
Tablo 2. Çocukların beslenme ve fırçalama alışkanlıklarının cinsiyet, periodontal durum ve ebeveynlerin eğitim seviyesine göre değerlendirilmesi

\begin{tabular}{|c|c|c|c|c|c|c|c|c|c|c|c|c|c|}
\hline & & \multicolumn{3}{|c|}{ Cinsiyet } & \multicolumn{3}{|c|}{ Periodontal Durum } & \multicolumn{3}{|c|}{ Anne Eğitim Sevlyesi } & \multicolumn{3}{|c|}{ Baba Egitim Seviyesi } \\
\hline & & Kiz & Erkek & & Sağlıklı & Gingivitis & & $\begin{array}{c}\text { ÎŌ } \\
\text { ve alth }\end{array}$ & $\begin{array}{c}\text { Lise } \\
\text { ve üzeri }\end{array}$ & & $\begin{array}{c}\text { ÎÖ } \\
\text { ve alt }\end{array}$ & $\begin{array}{c}\text { Lise } \\
\text { ve üzeri }\end{array}$ & \\
\hline & & n (\%) & n (\%) & $p^{+}$ & n $(\%)$ & n (\%) & $p^{+}$ & n (\%) & n (\%) & $p^{+}$ & n (\%) & n (\%) & $p^{+}$ \\
\hline \multirow{4}{*}{$\begin{array}{l}\text { Günlük ara } \\
\text { öğïn sayısı }\end{array}$} & Tüketmiyor & $11(13,3)$ & $6(9,0)$ & \multirow{4}{*}{0,029} & $10(14,3)$ & $7(8,8)$ & \multirow{4}{*}{0,542} & $13(14,0)$ & $4(7,0)$ & \multirow{4}{*}{0,351} & $8(11,4)$ & $9(11,3)$ & \multirow{4}{*}{0,098} \\
\hline & $1 \mathrm{kez}$ & $37(44,6)$ & $23(34,3)$ & & $29(41,4)$ & $31(38,8)$ & & $34(36,6)$ & $26(45,6)$ & & $28(40,0)$ & $32(40,0)$ & \\
\hline & 2 kez & $27(32,5)$ & $19(28,4)$ & & $18(25,7)$ & $28(35,0)$ & & $31(33,3)$ & $15(26,3)$ & & $21(30,0)$ & $25(31,3)$ & \\
\hline & 3 ve üzeri & $8(9,6)$ & $19(28,4)$ & & $13(18,6)$ & $14(17,6)$ & & $15(16,1)$ & $12(21,1)$ & & $13(18,6)$ & $14(17,5)$ & \\
\hline \multirow{5}{*}{$\begin{array}{l}\text { Günlük KH } \\
\text { tüketim sayıs }\end{array}$} & $1 \mathrm{kez}$ & $7(8,4)$ & $3(4,5)$ & \multirow{5}{*}{0,637} & $5(7,1)$ & $5(6,3)$ & \multirow{5}{*}{0,840} & $7(7,5)$ & $3(5,3)$ & \multirow{5}{*}{0,819} & $4(5,7)$ & $6(7,5)$ & \multirow{5}{*}{0,299} \\
\hline & 2 kez & $21(25,3)$ & $15(22,4)$ & & $18(25,7)$ & $18(22,5)$ & & $21(22,6)$ & $15(26,3)$ & & $14(20,0)$ & $22(27,5)$ & \\
\hline & $3 \mathrm{kez}$ & $36(43,4)$ & $27(40,3)$ & & $31(44,3)$ & $32(40,0)$ & & $37(39,8)$ & $26(45,6)$ & & $27(38,6)$ & $36(45,0)$ & \\
\hline & $4 \mathrm{kez}$ & $12(14,5)$ & $15(22,4)$ & & $11(15,7)$ & $16(20,0)$ & & $18(19,4)$ & $9(15,8)$ & & $16(22,9)$ & $11(13,8)$ & \\
\hline & 5 ve üzeri & $7(8,4)$ & $7(10,4)$ & & $5(7,1)$ & $9(11,3)$ & & $10(10,8)$ & $4(7,1)$ & & $9(12,9)$ & $5(6,3)$ & \\
\hline \multirow{4}{*}{$\begin{array}{l}\text { Günlük } \\
\text { sekerli içecek } \\
\text { tüketim sayısı }\end{array}$} & Tüketmiyor & $24(28,9)$ & $9(13,4)$ & \multirow{4}{*}{0,060} & $20(28,6)$ & $13(16,3)$ & \multirow{4}{*}{0,064} & $19(20,4)$ & $14(24,6)$ & \multirow{4}{*}{0,768} & $13(18,6)$ & $20(25,0)$ & \multirow{4}{*}{0,588} \\
\hline & $1 \mathrm{kez}$ & $36(43,4)$ & $36(53,7)$ & & $33(47,1)$ & $39(48,8)$ & & $46(49,5)$ & $26(45,6)$ & & $33(47,1)$ & $39(48,8)$ & \\
\hline & 2 kez & $22(26,5)$ & $18(26,9)$ & & $17(24,3)$ & $23(28,8)$ & & $24(25,8)$ & $16(28,1)$ & & $22(31,4)$ & $18(22,5)$ & \\
\hline & 3 ve üzeri & $1(1,2)$ & $4(6,0)$ & & $0(0,0)$ & $5(6,3)$ & & $4(4,3)$ & $1(1,8)$ & & $2(2,9)$ & $3(3,8)$ & \\
\hline \multirow{4}{*}{$\begin{array}{l}\text { Ara ögüündeki } \\
\text { KH içeriğgi }\end{array}$} & KH tüketmiyor & $11(13,3)$ & $6(9,0)$ & \multirow{4}{*}{0,233} & $10(14,3)$ & $7(8,8)$ & \multirow{4}{*}{0,468} & $13(14,0)$ & $4(7,0)$ & \multirow{4}{*}{0,236} & $8(11,4)$ & $9(11,3)$ & \multirow{4}{*}{0,486} \\
\hline & KH fakir & $18(21,7)$ & $9(13,4)$ & & $11(15,7)$ & $16(20,0)$ & & $13(14,0)$ & $14(24,0)$ & & $9(12,9)$ & $18(22,5)$ & \\
\hline & KH orta & $27(32,5)$ & $20(29,9)$ & & $19(27,1)$ & $28(35,0)$ & & $28(30,1)$ & $19(33,3)$ & & $24(34,3)$ & $23(28,8)$ & \\
\hline & $\mathrm{KH}$ zengin & $27(32,5)$ & $32(47,8)$ & & $30(42,9)$ & $29(36,3)$ & & $39(41,9)$ & $20(35,1)$ & & $29(41,4)$ & $30(37,5)$ & \\
\hline \multirow{4}{*}{$\begin{array}{l}\text { Firçalama } \\
\text { sakığı }\end{array}$} & Firçalamıyor & $7(8,4)$ & $8(11,9)$ & \multirow{4}{*}{0,777} & $1(1,4)$ & $14(17,5)$ & \multirow{4}{*}{0,000} & $13(14,0)$ & $2(3,5)$ & \multirow{4}{*}{0,110} & $12(17,1)$ & $3(3,8)$ & \multirow{4}{*}{0,045} \\
\hline & Haftada 2-3 kere & $19(22,9)$ & $12(17,9)$ & & $9(12,9)$ & $22(27,5)$ & & $21(22,0)$ & $10(17,5)$ & & $15(21,4)$ & $16(20,0)$ & \\
\hline & Günde 1 kere & $39(47,0)$ & $34(50,7)$ & & $40(57,1)$ & $33(41,3)$ & & $43(46,2)$ & $30(52,6)$ & & $31(44,3)$ & $42(52,5)$ & \\
\hline & Günde 2 kere & $18(21,7)$ & $13(19,4)$ & & $20(28,6)$ & $11(13,8)$ & & $16(17,2)$ & $15(26,3)$ & & $12(17,1)$ & $19(23,8)$ & \\
\hline & & $\begin{array}{c}\text { Ort } \pm \text { SS } \\
\text { (Ortanca) }\end{array}$ & $\begin{array}{c}\text { Ort } \pm \text { SS } \\
\text { (Ortanca) }\end{array}$ & $p^{+}$ & $\begin{array}{c}\text { Ort } \pm \text { SS } \\
\text { (Ortanca) }\end{array}$ & $\begin{array}{c}\text { Ort } \pm \text { SS } \\
\text { (Ortanca) }\end{array}$ & $p^{++}$ & $\begin{array}{c}\text { Ort } \pm \text { SS } \\
\text { (Ortanca) }\end{array}$ & $\begin{array}{c}\text { Ort } \pm S S \\
\text { (Ortanca) }\end{array}$ & $p^{++}$ & $\begin{array}{c}\text { Ort } \pm \text { SS } \\
\text { (Ortanca) }\end{array}$ & $\begin{array}{c}\text { Ort } \pm \text { SS } \\
\text { (Ortanca) }\end{array}$ & $p^{++}$ \\
\hline Furçalama süre & i (dk) & $\begin{array}{c}1,75 \pm 1,01 \\
(2,00)\end{array}$ & $\begin{array}{c}1,59 \pm 0,95 \\
(1,50)\end{array}$ & 0,342 & $\begin{array}{c}1,86 \pm 0,86 \\
(2,00)\end{array}$ & $\begin{array}{c}1,52 \pm 1,05 \\
(1,50)\end{array}$ & 0,000 & $\begin{array}{c}1,72 \pm 1,13 \\
(1,50)\end{array}$ & $\begin{array}{c}1,61 \pm 0,67 \\
(1,50)\end{array}$ & 0,765 & $\begin{array}{c}1,70 \pm 1,23 \\
(1,50)\end{array}$ & $\begin{array}{c}1,66 \pm 0,71 \\
(2,00)\end{array}$ & 0,582 \\
\hline
\end{tabular}

Tablo 3. Çocukların klinik parametrelerinin cinsiyete, periodontal durumlarına ve ebeveynlerin eğitim seviyesine göre değerlendirilmesi

\begin{tabular}{|c|c|c|c|c|c|c|c|c|c|c|c|c|}
\hline & \multicolumn{3}{|c|}{ Cinsiyet } & \multicolumn{3}{|c|}{ Periodontal Durum } & \multicolumn{3}{|c|}{ Anne Eg̈itim Seviyesi } & \multicolumn{3}{|c|}{ Baba E ğitim Seviyesi } \\
\hline & $\mathbf{K} \mathbf{z}$ & Erkek & & Sağhıkhı & Gingivitisli & & $\begin{array}{c}\text { I0̈ } \\
\text { ve altı }\end{array}$ & $\begin{array}{c}\text { Lise } \\
\text { ve üzeri }\end{array}$ & & $\begin{array}{c}\text { IÖ } \\
\text { ve altı }\end{array}$ & $\begin{array}{c}\text { Lise } \\
\text { ve üzeri }\end{array}$ & \\
\hline & $\begin{array}{c}\text { Ort } \pm \text { SS } \\
\text { (Ortanca) }\end{array}$ & $\begin{array}{c}\text { Ort } \pm \text { SS } \\
\text { (Ortanca) }\end{array}$ & $p$ & $\begin{array}{c}\text { Ort } \pm \text { SS } \\
\text { (Ortanca) }\end{array}$ & $\begin{array}{c}\text { Ort } \pm \text { SS } \\
\text { (Ortanca) }\end{array}$ & $p$ & $\begin{array}{c}\text { Ort } \pm \text { SS } \\
\text { (Ortanca) }\end{array}$ & $\begin{array}{c}\text { Ort } \pm S S \\
\text { (Ortanca) }\end{array}$ & $p$ & $\begin{array}{c}\text { Ort } \pm \text { SS } \\
\text { (Ortanca) }\end{array}$ & $\begin{array}{c}\text { Ort } \pm \text { SS } \\
\text { (Ortanca) }\end{array}$ & $p$ \\
\hline Pİ & $\begin{array}{c}0,85 \pm 0,52 \\
(0,85)\end{array}$ & $\begin{array}{c}0,85 \pm 0,51 \\
(0,69)\end{array}$ & 0,815 & $\begin{array}{c}0,38 \pm 0,17 \\
(0,36)\end{array}$ & $\begin{array}{c}1,27 \pm 0,32 \\
(1,30)\end{array}$ & 0,000 & $\begin{array}{c}0,88 \pm 0,53 \\
(0,85)\end{array}$ & $\begin{array}{c}0,81 \pm 0,49 \\
(0,69)\end{array}$ & 0,533 & $\begin{array}{c}0,90 \pm 0,53 \\
(0,87)\end{array}$ & $\begin{array}{c}0,81 \pm 0,50 \\
(0,67)\end{array}$ & 0,370 \\
\hline Gí & $\begin{array}{c}0,70 \pm 0,69 \\
(0,81)\end{array}$ & $\begin{array}{c}0,67 \pm 0,69 \\
(0,70)\end{array}$ & 0,786 & $\begin{array}{c}0,00 \pm 0,00 \\
(0,00)\end{array}$ & $\begin{array}{c}1,29 \pm 0,32 \\
(1,32)\end{array}$ & 0,000 & $\begin{array}{c}0,71 \pm 0,69 \\
(0,86)\end{array}$ & $\begin{array}{c}0,65 \pm 0,68 \\
(0,45)\end{array}$ & 0,753 & $\begin{array}{c}0,73 \pm 0,71 \\
(0,97)\end{array}$ & $\begin{array}{c}0,65 \pm 0,67 \\
(0,57)\end{array}$ & 0,474 \\
\hline$C P I$ & $\begin{array}{c}0,54 \pm 0,54 \\
(0,66)\end{array}$ & $\begin{array}{c}0,50 \pm 0,51 \\
(0,33)\end{array}$ & 0,614 & $\begin{array}{c}0,00 \pm 0,00 \\
(0,00)\end{array}$ & $\begin{array}{c}0,98 \pm 0,26 \\
(1,00)\end{array}$ & 0,000 & $\begin{array}{c}0,56 \pm 0,55 \\
(0,66)\end{array}$ & $\begin{array}{c}0,46 \pm 0,48 \\
(0,16)\end{array}$ & 0,189 & $\begin{array}{c}0,59 \pm 0,56 \\
(0,91)\end{array}$ & $\begin{array}{c}0,46 \pm 0,49 \\
(0,24)\end{array}$ & 0,114 \\
\hline dft+DMFT & $\begin{array}{c}4,40 \pm 2,74 \\
(4,00)\end{array}$ & $\begin{array}{c}4,11 \pm 2,45 \\
(4,00)\end{array}$ & 0,582 & $\begin{array}{c}4,00 \pm 2,64 \\
(4,00)\end{array}$ & $\begin{array}{c}4,52 \pm 2,57 \\
(4,00)\end{array}$ & 0,192 & $\begin{array}{c}4,45 \pm 2,32 \\
(4,00)\end{array}$ & $\begin{array}{c}4,00 \pm 3,02 \\
(4,00)\end{array}$ & 0,209 & $\begin{array}{c}4,35 \pm 2,22 \\
(4,00)\end{array}$ & $\begin{array}{c}4,21 \pm 2,92 \\
(4,00)\end{array}$ & 0,574 \\
\hline dfs+DMFs & $\begin{array}{c}8,85 \pm 6,94 \\
(7,00)\end{array}$ & $\begin{array}{c}8,92 \pm 7,99 \\
(7,00)\end{array}$ & 0,820 & $\begin{array}{c}9,02 \pm 8,01 \\
(7,50)\end{array}$ & $\begin{array}{c}8,76 \pm 6,88 \\
(7,00)\end{array}$ & 0,856 & $\begin{array}{c}9,15 \pm 6,55 \\
(8,00)\end{array}$ & $\begin{array}{c}8,45 \pm 8,67 \\
(6,00)\end{array}$ & 0,123 & $\begin{array}{c}9,45 \pm 6,61 \\
(8,00)\end{array}$ & $\begin{array}{c}8,38 \pm 8,04 \\
(6,50)\end{array}$ & 0,103 \\
\hline
\end{tabular}

İ̈: İlköğretim, Ort: Aritmetik ortalama, SS: Standart sapma, PI: Plak indeks, GI: Gingival indeks, CPI: Community periodontal index, Mann-Whitney U test, $p<0,05$. 
kızlar ve erkekler arasında klinik parametreler açısından istatistiksel olarak anlamlı fark bulunmadığı görüldü ( $p>0,05)$. Çocuklar periodontal durumlarına göre gruplandırıldığında, gingivitisli çocukların PI, Gi ve CPI değerlerinin beklendiği gibi sağlıklı çocuklara kıyasla istatistiksel olarak anlamlı yüksek olduğu gözlenirken $(p<0,01)$, dental parametreler açısından gruplar arasında herhangi bir fark saptanmadı ( $p>0,05)$. Farklı eğitim düzeylerine sahip ebeveynlerin çocuklarında periodontal klinik parametreler benzerdi( $p>0,05)$.

Çocukların beslenme ve fırçalama alışkanlıklarına göre klinik bulguları Tablo 4'te gösterilmektedir. Çocukların günlük ara öğün ve karbonhidrat tüketim sayıları, ara öğünde tükettikleri karbonhidrat içeriğine göre periodontal parametreler değerlendirildiğinde istatistiksel olarak anlamlı fark bulunmadı ( $p>0,05)$. Ancak, şekerli içecek tüketim sayısı özellikle 3 ve üzeri olan çocukların periodontal parametre değerlerinin istatistiksel olarak anlamlı yüksek olduğu gözlendi $(p<0,05)$. Çocukların beslenme alışkanlıklarına göre dft+DMFT ve dsf+DMFS verileri incelendiğinde, istatistiksel olarak anlamlı fark saptanmadı ( $p>0,05)$. Fırçalama sıklığına göre gruplara ayrılan çocuklarda PI, Gi ve CPI değerleri açısından istatistiksel olarak anlamlı fark saptandı $(p<0,01)$. Buna göre çocuklar dişlerini daha sık fırçaladıkça, her üç parametrede de değerlerin azaldığı tespit edildi. Fırçalama sıklığı birbirinden farklı olan çocukların dental bulguları arasında istatistiksel olarak anlamlı herhangi bir fark saptanmadı $(p>0,05)$ (Tablo 4).

Tablo 4. Çocukların beslenme ve fırçalama alışkanlıklarına göre klinik parametrelerin değerlendirilmesi

\begin{tabular}{|c|c|c|c|c|c|c|}
\hline & & $\mathrm{PI}$ & GI & $C P I$ & Aft+DMFT & Afs+DMrs \\
\hline & & $\begin{array}{c}\text { Ortess } \\
\text { (Ortanca) }\end{array}$ & $\begin{array}{l}\text { Ortt5s } \\
\text { (Ortanca) }\end{array}$ & $\begin{array}{c}\text { Orttss } \\
\text { (Ortanca) }\end{array}$ & $\begin{array}{c}\text { Ortass } \\
\text { (Ortanca) }\end{array}$ & $\begin{array}{r}\text { Ortiss } \\
\text { (Ortanca) }\end{array}$ \\
\hline \multirow{7}{*}{$\begin{array}{l}\text { Gâmlïk } \\
\text { ara } \\
\text { ogận sayıs }\end{array}$} & Túketmiyor & $\begin{array}{c}0,73+0,51 \\
(0,52)\end{array}$ & $\begin{array}{c}0,5410,65 \\
(0,000\end{array}$ & $\begin{array}{l}4,64+2,02 \\
(5000\end{array}$ & $\begin{array}{c}9,52+6,16 \\
8000\end{array}$ & $0,41 \pm 0,51$ \\
\hline & 1 kez & $0,82 \pm 0.51$ & $0,65 \pm 0.68$ & $3,9602,86$ & $8.50+8,33$ & $0,50 \pm 0,51$ \\
\hline & 2 ker & $0,90 \pm 0,52$ & $0,77 \pm 0.68$ & $4.65+2,27$ & $9.80 \pm 7.17$ & $0.00 \div 0.55$ \\
\hline & & $(0,96)$ & $(0,93)$ & $(4,00)$ & $(8,00)$ & $(0,74)$ \\
\hline & 3 ve äreri & $0,93 \pm 0,53$ & $0,72+0,74$ & $4,11 \pm 2,90$ & $7,6000.37$ & $0.51+0,53$ \\
\hline & & $(0,88)$ & $(0,80)$ & $(4,00)$ & $(7,00)$ & $(0,33)$ \\
\hline & $p$ & 0,567 & 0,615 & 0,507 & 0,306 & 0,472 \\
\hline \multirow{8}{*}{$\begin{array}{l}\text { Günlük } \\
\text { KH } \\
\text { tüketim } \\
\text { sagys }\end{array}$} & 1 kez & $\begin{array}{c}0,92+0,04 \\
(0,95)\end{array}$ & $\begin{array}{c}0,76 \pm 0,81 \\
(0,04)\end{array}$ & $\begin{array}{c}4,70+2,21 \\
(5,00)\end{array}$ & $\begin{array}{c}9,60 \pm 6,83 \\
(8.50)\end{array}$ & $\begin{array}{c}0,53 \pm 0,56 \\
(0,50)\end{array}$ \\
\hline & $2 \mathrm{kez}$ & $\begin{array}{l}0,8000,53 \\
(0,54)\end{array}$ & $\begin{array}{l}0,62 \pm 0,69 \\
(0,19)\end{array}$ & $\begin{array}{c}4,27 \pm 2,71 \\
(4,00)\end{array}$ & $\begin{array}{c}9,41+8,32 \\
(7,50)\end{array}$ & $\begin{array}{c}0,47 \pm 0,51 \\
(0,10)\end{array}$ \\
\hline & 3 kex & $0,85+0,52$ & $0,66 \pm 0,69$ & $4,31+2,50$ & $8,93 \div 7,60$ & $0,49 \div 0,52$ \\
\hline & & $(0,71)$ & $(0,74)$ & $(4,00)$ & $(0,00)$ & $(0,10)$ \\
\hline & t kex & $\begin{array}{l}0,87 \pm 0,45 \\
(0,98)\end{array}$ & $\begin{array}{c}0,74 \pm 0,68 \\
(1,00)\end{array}$ & $\begin{array}{c}4,44+2,92 \\
(4,00)\end{array}$ & $\begin{array}{c}8,55 \div 7,10 \\
8,00)\end{array}$ & $\begin{array}{c}0,62 \pm 0,58 \\
0,000\end{array}$ \\
\hline & 5 ve ürert & $0,92+0,51$ & $0,80 \pm 0,06$ & $\begin{array}{c}\quad[3,50+2,21 \\
3\end{array}$ & $7,42+5,48$ & $0.58 \div 0,50$ \\
\hline & & $(0,89)$ & $(0.89)$ & $(4,00)$ & $(0,00)$ & $(0,60)$ \\
\hline & $\bar{p}$ & 0,954 & 0,923 & 0,793 & 0,971 & 0,729 \\
\hline \multirow{7}{*}{$\begin{array}{l}\text { Günlük } \\
\text { seherill } \\
\text { icececk } \\
\text { tiketim } \\
\text { sayys }\end{array}$} & Tüketmiyor & $\begin{array}{c}0,65 \pm 0,48 \\
\{0,39\rangle\end{array}$ & $\begin{array}{c}0,45 \pm 0,61 \\
(0,00)\end{array}$ & $\begin{array}{c}4,27 \pm 2,84 \\
(4,00)\end{array}$ & $\begin{array}{c}9,48 \pm 7,31 \\
(8,00)\end{array}$ & $\begin{array}{c}0.35+0,47 \\
(0,00)\end{array}$ \\
\hline & 1 ker & $\begin{array}{l}0,91+0,55 \\
(0.80)\end{array}$ & $\begin{array}{c}0,72 \div 0,71 \\
089\end{array}$ & $4,30 \pm 2,48$ & $9,47 \pm 7,72$ & $0.54+0,54$ \\
\hline & 2 kez & $0.89 \pm 0.45$ & $0,32 \pm 0,66$ & $395 \pm 2.56$ & $\begin{array}{c}(8,009) \\
720 \pm 7,03\end{array}$ & $\begin{array}{c}10,49) \\
0.54+0.51\end{array}$ \\
\hline & & $(0.83)$ & $(0,82)$ & $(4,00)$ & $(5.50)$ & $0.66)$ \\
\hline & 3 ve üreri & $1,14 \pm 0,25$ & $1,52+0,28$ & $6,60 \pm 2,88$ & $10,00 \pm 6,04$ & $1,13+0,29$ \\
\hline & & $(1,15)$ & $(1,46)$ & $(7.00)$ & $(9,00\}$ & $(1,00)$ \\
\hline & $p$ & 0,038 & 0,018 & 0.363 & 0.211 & 0,027 \\
\hline \multirow{8}{*}{ 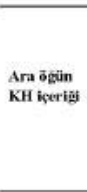 } & Taketmigor & $\begin{array}{l}0,73+0,51 \\
(0.52)\end{array}$ & $\begin{array}{c}0.54 \pm 0,68 \\
(0,00)\end{array}$ & $\begin{array}{c}4,64 \pm 2,02 \\
(5,001)\end{array}$ & $\begin{array}{c}9.52+6.16 \\
(8.00)\end{array}$ & $\begin{array}{c}0,41 \pm 0,51 \\
(0,00)\end{array}$ \\
\hline & KH fakir & $0,87 \pm 0,49$ & $0,71 \pm 0,67$ & $4,74 \pm 2,61$ & $9,03 \pm 7,61$ & $0,52 \div 0,47$ \\
\hline & & $(0.87)$ & $(0,81)$ & $(4,00)$ & $(7,00)$ & $(0,60)$ \\
\hline & KH orta & $0,89 \div 0,51$ & $0,77 \pm 0,69$ & $3,85 \pm 2,61$ & $793 \pm 6,63$ & $0.59 \div 0.55$ \\
\hline & & $(0,97)$ & $(0,97)$ & $(4,00)$ & $(6,00)$ & $(0,83)$ \\
\hline & KH rengin & $0,85 \pm 0,54$ & $0,65 \pm 0,70$ & $4,30+2,76$ & $9,38+8,27$ & $0,50 \div 0,53$ \\
\hline & & $(0,71)$ & $(0,00)$ & $(4,00)$ & $(0.00)$ & $(0,00)$ \\
\hline & $\bar{p}$ & 0.708 & 0.607 & 0,444 & 0,741 & 0,554 \\
\hline \multirow{7}{*}{$\begin{array}{l}\text { Frcalama } \\
\text { saklä́ }\end{array}$} & Firçalameyor & $\begin{array}{c}1.43 \pm 0.33 \\
0.383\end{array}$ & $\begin{array}{c}1,40 \pm 0,45 \\
(1,50)\end{array}$ & $\begin{array}{c}1,08 \pm 0,34 \\
01.10\end{array}$ & $\begin{array}{l}4,73+2,60 \\
(4,00)\end{array}$ & $\begin{array}{c}10,10 \pm 7,80 \\
18,00\end{array}$ \\
\hline & & $(1,38)$ & $(1,50)$ & $\frac{(1,15)}{0.450}$ & $\frac{(4,00)}{490,270}$ & $\frac{(8,00)}{0.01070}$ \\
\hline & Hathada. $2.3 \mathrm{kez}$ & $\begin{array}{l}1,090,0,51 \\
(1,25)\end{array}$ & 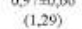 & $\begin{array}{l}0,1,00) \\
(1,00)\end{array}$ & $(5,00)$ & $\begin{array}{l}0,01 \pm 1,00) \\
(8,00)\end{array}$ \\
\hline & & $0.74 \pm 0,47$ & $0.55 \pm 0.65$ & $0.42 \pm 0.49$ & $4,00 \pm 2,53$ & $8,45 \pm 7,06$ \\
\hline & Günde $1 \mathrm{hes}$ & $(0,62)$ & $\{0,00\}$ & $(0,00)$ & $(4,00)$ & $(7,00)$ \\
\hline & Günde 2 hez & $\begin{array}{c}0,61 \pm 0,41 \\
(0,51)\end{array}$ & $\begin{array}{c}0,37 \pm 0,56 \\
(0,00)\end{array}$ & $\begin{array}{c}0,27 \pm 0,43 \\
(0,00)\end{array}$ & $\begin{array}{c}4,09+2,58 \\
(4,000)\end{array}$ & $\begin{array}{c}8.58 \pm 8,14 \\
(7,00)\end{array}$ \\
\hline & n & $\frac{(0.51)}{0.000}$ & $\begin{array}{l}(0,00) \\
0.000\end{array}$ & $(0,00)$ & $\frac{(4,00)}{0.352}$ & $\frac{(7,00)}{0,671}$ \\
\hline
\end{tabular}

Ort: Aritnetik ortalama, SS: Standart sapma. KH: Karbonhidrat, PI: Plak indeks, Gl: Gineival indeks, CPI: Commenity periadonzal indeks Kraskal Walles test, $p<a, 0$,

\section{TARTIŞMA}

Çocuklar doğdukları günden itibaren ebeveynlerinin davranışlarının ve alışkanlıklarının etkisi altındadırlar ve onlardan edindikleri fırçalama ve beslenme alışkanlıkları doğrudan çocuğun ağız sağlığı durumuna yansımaktadır. ${ }^{19}$ Sıklıkla görülen diş çürükleri ve periodontal hastalıklar, çocuklarda ağız ve diş sağlığını olumsuz yönde etkiler. Çocukluk döneminde en sık görülen periodontal hastalık, plağa bağlı gingivitistir ve birincil etkeni mikrobiyal dental plaktır. Çocuklarda gingivitis prevalansının en fazla görüldüğü dönem olan puberte döneminde seks hormonlarının seviyesi damarsal geçirgenliği artırarak mikrobiyal dental plağa karşı doku cevabında belirgin artışa neden olur. ${ }^{20} \mathrm{Bu}$ durumda, puberte döneminde ağız sağlığının korunmasında plak kontrolünün önemi artmaktadır.

Karbonhidrat içerikli gıdaların tüketim sıklığındaki artışın çocuklarda diş çürüğü ve periodontal hastalık riskini artırdığı bilinen bir gerçektir. ${ }^{2}$ Diş çürüğü özellikle şeker başta olmak üzere fermente edilebilen karbonhidratların varlığında gelişebilmektedir. ${ }^{21}$ Bunun yanında periodontal hastalıkların görülme sıklığı da fazla karbonhidrat tüketiminden etkilenebilmektedir. Özellikle işlenmiş karbonhidratların, oksidatif stresi artırarak periodontal hastalıklarda yıkıma sebep olan proenflamatuvar sitokin salınımını artırdığı ve hastalığın ilerlemesini hızlandırdığı gösterilmiştir. ${ }^{22}$ Lula ve ark. ${ }^{23}$ aşırı şeker tüketimiyle adipoz dokuda ve insülin direncinde meydana gelen artışın periodontal hastalıklarla ilişkili olduğunu belirtmişlerdir. Ayrıca şekerli içecek tüketim sıklığının artması, açlık hissini ve şekerli gıdalara olan eğilimi artırdığı için toplumun vücut ve ağız sağlığını olumsuz yönde etkilediği vurgulanmaktadır. ${ }^{24}$ Çalışmamıza katılan çocukların \%40'ının günde en az 1 kez ara öğün alışkanlığı olduğu ve bunların da yaklaşık \%39'unun da karbonhidrattan zengin ara öğün tükettiği saptandı. Ayrıca çocukların \%69'unun günde en az 3 kere karbonhidrat tükettiği ve çalışmaya katılan çocukların yarısına yakınının da günde en az bir kez şekerli içecek tükettiği gözlendi.

Beslenme alışkanlıklarına göre periodontal bulgular incelendiğinde, günlük ara öğün sayısı ve karbonhidrat içeriği, günlük karbonhidrat tüketim sayısına göre gruplandırılan çocuklar arasında Pi, Gi ve CPI değerleri açısından fark bulunmazken; günlük şekerli içecek tüketen çocuklarda PI ve Gi ortalamalarının daha yüksek olduğu gözlendi. Bu bulgu, şeker içerikli ürünleri tüketenlerde gingivitis sıklığının arttığına dair bulguları destekler niteliktedir. ${ }^{25}$ Beslenme alışkanlıklarına göre dental bulgular incelendiğinde ise, dft+DMFT ve dfs+DMFS değerleri açısından herhangi bir fark saptanmadı. Literatürde karbonhidrat içeren, şeker ilave edilmiş karyojenik gıdalarla beslenmenin DMFT skorları üzerine olumsuz etki gösterdiğini gösteren çalışmaların 2, 26 bulgularıyla örtüşmeyen sonuçlarımız, çürük oluşumunda beslenme alışkanlığı dışında, yaş, tükürük 
kalitesi, mikrobiyolojik özellikler, diş anatomisi gibi diğer faktörlerin de önemli olduğunu göstermektedir.

Çocuklarda sık görülen diş çürükleri ve dişeti hastalıklarından korunmanın temel prensibi düzenli diş fırçalama alışkanlığıdır. ${ }^{27}$ Tseveenjav ve ark. ${ }^{28}$ yeterli diş fırçalama alışkanlığının yeni çürük oluşumunu önemli ölçüde azalttığını ve günlük fırçalama sıklığının günde 2 kereden daha az olmasının ağız sağlığının korunması açısından riskli olduğunu bildirmişlerdir. Çalışmamızdaki çocukların diş fırçalama süreleri 0,5 ila 5 dakika aralığında değişmekte olup ortalama 1,68 $\pm 0,98$ dakika olarak hesaplandı. Fırçalama sıklıkları incelendiğindeyse günde 2 kez diş fırçalayanların oranının sadece $\% 20,7$ olduğu gözlendi. Fırçalama sıklığına göre periodontal ve dental parametrelere bakıldığında günde en az 1 kez diş fırçalayan çocuklarda hiç fırçalamayan ve haftada 2-3 kez fırçalayanlara göre Pi, Gi ve CPI ortalamalarının, literatürdeki bilgilere paralel bir şekilde düşük olduğu saptandı. ${ }^{29}$ Ancak dental parametreler olan dft+DMFT ve dfs+DMFS ortalamaları açısından fırçalama sıklığına göre çocuklar arasında fark olmadığı tespit edildi. Bu sonuç yine çürük oluşumunda fırçalama sıklığı dışında başka faktörlerin de etkili olabileceğini destekler niteliktedir.

Ebeveynlerin ağız sağlığı ile ilgili bilgileri, sosyoekonomik durum ve eğitim düzeyleri, çocukların ağız sağlığı durumunu doğrudan etkilemektedir. Çocuklar özellikle okul öncesi dönemde ailelerinin söz ve davranışlarından etkilenirler ve onları taklit etmeye başlarlar. ${ }^{30}$ Çalışma popülasyonuna bakıldığında eğitim seviyesi ilköğretim ve altı olan annelerin çocukları ile eğitim seviyesi lise ve üzeri olan annelerin çocukları arasında diş fırçalama sıklığı ve süresi açısından fark bulunmadı. Fırçalama alışkanlığı baba eğitim seviyesine göre karşılaştırıldığında ilköğretim ve altı eğitim seviyesine sahip babaların çocukları ile lise ve üzeri eğitim seviyesine sahip babaların çocukları arasında fırçalama süresi açısından fark bulunmazken; fırçalama sıklığı açısından anlamlı fark bulundu. Pardi ve ark.'nın ${ }^{31}$ çocukların ağız sağlığı durumunu inceledikleri çalışmalarında, baba eğitim seviyesinin çocukların ağız sağlığını belirlemede etkili bir faktör olduğunu tespit etmişlerdir. Erdoğan ve ark. ${ }^{32}$ tıp fakültesi öğrencilerinin ağız bakımına verdikleri önemi değerlendirdikleri çalışmalarında söz konusu alışkanlıkların babanın eğitim ve sosyoekonomik seviyesi ile ilişkili olduğunu bulmuş, daha yüksek sosyoekonomik-sosyokültürel seviyedeki ebeveynlerin çocuklarında ağız hijyeninin daha iyi ve sağlam diş sayısının daha fazla olduğunu tespit etmişlerdir. Fırçalama sıklığı ile baba eğitim seviyesi arasında bulduğumuz ilişki, çalışmalardan elde edilen sonuçlar ile paralellik göstermektedir.

Fırçalama alışkanlıkları gibi beslenme alışkanlıkları da ebeveynlerin eğitim seviyesinden etkilenebilmektedir. ${ }^{33}$ Çalışmamızda anne ve baba eğitim seviyesine göre çocukların beslenme alışkanlıkları incelendiğinde gruplar- daki çocukların beslenme alışkanlıklarının benzer olduğu görüldü. Sotos-Prieto ve ark. ${ }^{33}$ eğitim seviyesi düşük olan ailelerin çocuklarında beslenme alışkanlıklarının daha düzensiz olduğunu, bu alışkanlığın ailenin sosyoekonomik seviyesiyle doğrudan ilişkili olduğunu belirtmişlerdir. Çalışmamızda anne veya baba eğitim seviyesi farklı olan çocuklar arasında beslenme alışkanlıkları açısından fark görülmemesi popülasyonumuzu oluşturan ebeveynlerin beslenme alışkanlıklarının benzer olmasına bağlanabilir. Anne veya baba eğitim düzeylerine göre gruplandırılan çocuklar arasında periodontal ve dental parametreler açısından fark tespit edilmedi. Bu durum çalışma grubumuzun yakın sosyokültürel ve sosyoekonomik seviyeye sahip ailelerin çocuklarından oluşması ile açıklanabilir. Ancak çalışmaya dahil edilen çocukların ebeveynlerinin çoğunluğunun eğitim durumunun benzer olması nedeniyle bulguların Türk toplumunu tam olarak yansıtmamış olabileceği göz önünde bulundurulmalıdır.

Beslenme ve fırçalama alışkanlıkları kızlar ve erkekler arasında değişkenlik gösterebilir. ${ }^{34,35}$ Çalışmamızda beslenme alışkanlıkları cinsiyet açısından değerlendirildiğinde kızlar ve erkekler arasında günlük karbonhidrat tüketim sayısı, ara öğünlerdeki karbonhidrat içeriği ve şekerli içecek tüketim sayısı açısından fark bulunmazken, günlük ara öğün sayısı açısından anlamlı fark bulundu. Günde 3 ve üzeri ara öğün tüketen erkeklerin oranının $(\% 28,4) \mathrm{kIz}-$ ların oranından $(\% 9,6)$ daha yüksek olduğu tespit edildi. Bu sonuç, ülkemizde yapılan bir çalışmada vurgulanan ${ }^{34}$ erkeklerin kızlara göre daha düzensiz beslendiği sonucuyla uyumludur. Cinsiyetlere göre fırçalama alışkanlıklarına bakıldığında, diş fırçalama sıklığı ve süresinin her iki cinsiyette de benzer olduğu gözlendi. Kızların fırçalama alışkanlıklarının daha düzenli olması nedeniyle ağız sağlığı durumlarının erkeklere göre daha iyi olduğunu bildiren çalışmalar bulunmasına karşın, ${ }^{27,35}$ çalışmamızda periodontal ve dental sağlığı değerlendirdiğimiz parametreler açısından kızlar ve erkekler arasında fark tespit edilmedi. Periodontal olarak sağlıklı ve gingivitisli çocuklar arasında PI, Gi ve CPI değerleri karşılaştıııldığında, bu değerlerin gingivitisli çocuklarda daha yüksek olduğu ancak dft+DMFT ve dfs+DMFS değerleri açısından gruplar arası farkın olmadığı gözlendi. Buna ek olarak periodontal olarak sağlıklı ve gingivitisli çocuklar arasında beslenme alışkanlıkları açısından fark tespit edilmedi. Çocukların fırçalama alışkanlıkları periodontal durumlarına göre incelendiğinde sağlıklı çocuklarda hem ortalama fırçalama süresinin hem de fırçalama sıklığının gingivitisli çocuklardan daha fazla olduğu görüldü. Beklendiği gibi, sağlıklı çocukların gingivitisli çocuklara göre dişlerini daha düzenli fırçaladıkları tespit edildi. Bu sonuç periodontal hastalığın önlenmesinde diş fırçalama alışkanlıklarının önemini bir kez daha ortaya koymaktadır. 


\section{SONUÇ}

Bu çalışmanın sınırları dahilinde, elde ettiğimiz sonuçlar araştırmanın yürütüldüğü çocukların beslenme alışkanlığının karbonhidrattan zengin ve ara öğün sayısının yüksek olduğunu, ağız hijyeni gerekliliklerini yerine getirmede yetersiz kaldıklarını göstermektedir. Buna ek olarak, ebeveynlerin eğitim seviyesinin çocukların beslenme ve fırçalama alışkanlıkları üzerine olan etkilerini destekleyen bir kanıt elde edilemedi. Bulgularımız çocuklarda karbonhidrattan zengin ve ara öğün sayısının sık olduğu bir beslenmenin çürük oluşumunda tek başına yeterli olmadığını göstermekte, periodontal hastalığın önlenmesinde ağız bakım alışkanlığı ve uygulamalarının önemini vurgulamaktadır.

\section{KAYNAKLAR}

1- Krol DM, Nedley MP. Dental caries: state of the science for the most common chronic disease of childhood. Adv Pediatr 2007; 54: 215-239.

2- Akyüz S, Doğan BN, Kuru L. Dietary habits and oral health of children in decidious, early and late mixed dentition. Journal of Marmara University Institute of Health Sciences 2012; 2(3): 113-118.

3- Drummond BK, Brosnan MG, Leichter JW. Management of periodontal health in children: pediatric dentistry and periodontology interface. Periodontol 2000 2017; 74(1): 158-167.

4- Jürgensen N, Petersen PE. Oral health and the impact of socio-behavioural factors in a cross sectional survey of 12-year old school children in Laos. BMC Oral Health 2009; 9: 29.

5- Kolawole KA, Oziegbe EO, Bamise CT. Oral hygiene measures and the periodontal status of school children. Int J Dent Hyg 2011; 9(2): 143-148.

6- Villarosa AR, George D, Ramjan LM, Srinivas R, George

A. The role of dental practitioners in addressing overweight and obesity among children: A scoping review of current interventions and strategies. Obes Res Clin Pract 2018; 12(5): 405-415.

7- Agostini BA, Machry RV, Teixeira CR, Piovesan C, Oliveira MD ve ark. Self-perceived oral health influences tooth brushing in preschool children. Braz Dent J. 2014; 25(3): 248-252.

8- Bretz WA, Corby P, Schork N, Hart TC. Evidence of a contribution of genetic factors to dental caries risk. J Evid Based Dent Pract 2003; 3(4): 185-189.

9- Anil S, Anand PS. Early childhood caries: prevalence, risk factors and prevention. Front Pediatr 2017; 5: 157.

10- Knight ET, Liu J, Seymour GJ, Faggion CM Jr, Cullinan MP. Risk factors that may modify the innate and adaptive immune responses in periodontal diseases. Periodontol 2000 2016; 71(1): 22-51.

11- Dye BA, Vargas CM, Lee JJ, Magder L, Tinanoff N.
Assessing the relationship between children's oral health status and that of their mothers. J Am Dent Assoc 2011; 142(2): 173-183.

12- Dagon N, Ratson T, Peretz B, Blumer S. Maternal knowledge of oral health of children aged 1-4 years. J Clin Pediatr Dent 2019; 43(2): 116-120.

13- Hiratsuka VY, Robinson JM, Greenlee R, Refaat A. Oral health beliefs and oral hygiene behaviours among parents of urban Alaska Native children. Int J Circumpolar Health 2019; 78(1): 1586274.

14- Marshall TA, Eichenberger-Gilmore JM, Broffitt BA, Warren JJ, Levy SM. Dental caries and childhood obesity: roles of diet and socioeconomic status. Community Dent Oral Epidemiol 2007; 35(6): 449-458.

15- Loe H, Sillness J. Periodontal disease in pregnancy. I. Prevalence and Severity. Acta Odontol Scand 1963; 21: 533-551.

16- Schuller AA, Holst D. Oral status indicators DMFT and FS-T: reflections on index selection. Eur J Oral Sci 2001; 109(3): 155-159.

17- Radic M, Benjak T, Vukres VD, Rotim Ž, Zore IF. Presentation of DMFT/dmft Index in Croatia and Europe. Acta Stomatol Croat 2015; 49(4): 275-284.

18- Silness J, Loe H. Periodontal disease in pregnancy. II. Correlation between oral hygiene and periodontal condition. Acta Odontol Scand 1964; 22: 121-135.

19- Pflipsen $M$, Zenchenko $Y$. Nutrition for oral health and oral manifestations of poor nutrition and unhealthy habits. Gen Dent 2017; 65(6): 36-43.

20- Tiainen L, Asikainen S, Saxén L. Puberty-associated gingivitis. Community Dent Oral Epidemiol 1992; 20(2): 87-89.

21- Hujoel PP, Lingström P. Nutrition, dental caries and periodontal disease: a narrative review. J Clin Periodontol 2017; 44(Suppl 18): S79-S84.

22- Raindi D. Nutrition and periodontal disease. Dent Update 2016; 43(1): 66-8, 71-72.

23- Lula EC, Ribeiro CC, Hugo FN, Alves CN, Silva AA. Added sugars and periodontal disease in young adults: an analysis of NHANES III data. Am J Clin Nutr 2014; 100(4): $1182-1187$.

24- Vartanian LR, Schwartz MB, Brownell KD. Effects of soft drink consumption on nutrition and health: a systematic review and meta-analysis. Am J Public Health 2007; 97(4): 667-675.

25- Clancy KL, Goldberg HJ, Ritz A. Snack food consumption of 12 year old inner-city children and its relationship to oral health. J Public Health Dent 1978; 38(3): 227-234.

26- Ismail Al. Food cariogenicity in Americans aged from 9 to 29 years assessed in a national cross-sectional survey, 1971-74. J Dent Res 1986; 65(12): 1435-1440.

27- Altun $C$, Güven $G$, Başak F, Akbulut E. Altı-onbir yaş grubu çocukların ağız-diş sağlığı yönünden değerlendi- 
rilmesi. Gülhane Tıp Dergisi 2005; 47(2): 114-118.

28- Tseveenjav $B$, Suominen $A L$, Hausen $H$, Vehkalahti MM. The role of sugar, xylitol, toothburshing frequency, and use of flouride toothpaste in maintenance of adults' dental health: findings from the Finnish National Health 2000 Survey. Eur J Oral Sci 2011; 119(1): 40-47.

29- Vishwanathaiah S. Knowledge, attitudes, and oral health practices of school children in Davangere. Int $\mathrm{J}$ Clin Pediatr Dent 2016; 9(2): 172-176.

30- Şahin S, Saygun İ, Enhoş Ş, Akyol M, Altuğ A ve ark. Eğitim düzeyinin genç erişkin erkeklerde ağız sağlığına etkisinin değerlendirilmesi. Gazi Üniversitesi Dii Hekimliği Fakültesi Dergisi 2009; 26(3): 133-139.

31- Pardi V, Kopycka-Kedzierawski DT, Billings RJ, Pereira $\mathrm{SM}$, de Meneghim M ve ark. Assessment of caries experience in 12-year-old adolescents in Piracicaba, Sao Paulo, Brazil. Oral Health Prev Dent 2010; 8(4): 361-367.

32- Erdoğan A, Bozkurt A, Ergin A, Topaloğlu S, Aydın A ve ark. Pamukkale Üniversitesi Tıp Fakültesi öğrencilerinde ağız-diş sağlığının değerlendirilmesi. Pamukkale Tıp Dergisi 2015; (1): 1-9.

33- Sotos-Prieto M, Santos-Beneit G, Pocock S, Redondo $J$, Fuster $V$ ve ark. Parental and self-reported dietary and physical activity habits in pre-school children and their socio-economic determinants. Public Health Nutrition 2015; 18(2): 275-285.

34- Demirezen E, Coşansu G. Adölesan çağı öğrencilerde beslenme alışkanlıklarının değerlendirilmesi. STDE/Sürekli Tıp Eğitimi Dergisi 2005; 14(8): 174-178.

35- Kudirkaite I, Lopatiene K, Zubiene J, Saldunaite K. Age and gender influence on oral hygiene among adolescents with fixed orthodontic appliances. Stomatologija 2016; 18(2): 61-65. 